Research Article

\title{
A study on the drug prescribing pattern in acute, recurrent and chronic pharyngitis at a tertiary care hospital
}

\author{
Deepa Ranabovi ${ }^{1}$, Jyothi Ramesh ${ }^{1} *$, Jagannath Bisanna ${ }^{2}$, \\ Pundarikaksha Hulikallu Purushothama ${ }^{1}$
}

\begin{abstract}
${ }^{1}$ Department of Pharmacology,
${ }^{2}$ Department of ENT,

Kempegowda Institute of

Medical Sciences, Bangalore,

Karnataka, India
\end{abstract}

Received: 20 May 2016

Accepted: 13 June 2016

\section{*Correspondence to:}

Dr. Jyothi Ramesh,

Email: sanjyothi03@gmail.com

Copyright: (c) the author(s), publisher and licensee Medip Academy. This is an openaccess article distributed under the terms of the Creative Commons Attribution NonCommercial License, which permits unrestricted noncommercial use, distribution, and reproduction in any medium, provided the original work is properly cited.

\begin{abstract}
Background: Pharyngitis, or sore throat, is often caused by infection. Common respiratory viruses account for the vast majority of cases, and these are usually self-limited. Bacteria are also important etiologic agents, and, when identified properly, may be treated with antibacterial, resulting in decreased local symptoms and prevention of serious sequelae. The objective of this study was to determine the drug prescribing pattern in acute, recurrent and chronic bacterial pharyngitis and to assess the efficacy and tolerability of AMAs.

Methods: 50 subjects of either gender were included in the study to assess the prescribing pattern in acute, recurrent and chronic pharyngitis by purposive sampling method.

Results: 94\% subjects were between 16-45 years and mean age was $33.06 \pm 13.50$. $96 \%$ were from lower middle and upper lower class. Presenting complaints were sore-throat with fever in all the subjects, Co-amoxiclav was the most commonly used antibiotic $(48 \%)$ and others were cefpodoxime+clavulanic acid $(36 \%)$, cefadroxil+clavulanic acid $(8 \%)$, cefpodoxime $(4 \%)$, cefuroxime $(2 \%)$ and cefixime $(2 \%)$. Concomitant medications used were NSAIDs and decongestants/mucolytic. The AMAs showed good tolerability with mild and self-limiting adverse effects which did not require discontinuation.

Conclusions: Acute, recurrent and chronic bacterial pharyngitis can be effectively treated by empirical use of various antimicrobials. Co-amoxiclav can be considered as the mainstay/primary option because of the proven efficacy, good tolerability and low cost.
\end{abstract}

Keywords: Antimicrobials, Non-steroidal anti-inflammatory drugs, Bacterial Pharyngitis

\section{INTRODUCTION}

Pharyngitis is the inflammation of the mucus membranes of the pharynx, presenting commonly with sore throat, malaise, fever, cough and nasal congestion, which is usually treated with simple therapy directed at symptomatic relief. It can be acute, recurrent or chronic. In majority of acute cases, infection is not the cause, and where the infection is the cause, most of them are caused by viral infections followed by bacterial, and rarely fungal. Among the bacterial pathogens, group-A beta hemolytic streptococcus (GABHS) assume a special significance because of its suppurative and nonsuppurative complications like; retropharyngeal abscess, peritonsillar abscess, sinusitis, cervical lymphadenitis, otitis media, rheumatic fever (RF) and rheumatic heart disease (RHD). Recurrent pharyngitis is more than 3 episodes of acute pharyngitis within 12 months of period with positive laboratory report. ${ }^{1,2}$ Chronic pharyngitis is a chronic inflammatory condition of the pharynx, characterized by hypertrophy of mucosa, seromucinous glands and subepithelial lymphoid follicles. ${ }^{2,3}$

Many antimicrobial agents (AMAs) including antibacterial, antiviral and antifungal agents are used in the treatment and prophylaxis of pharyngitis. The pattern of AMA use may vary from hospital to hospital and in different geographical areas depending on the nature of infections, prevalent strains of pathogens, the pattern of susceptibility/resistance and cost/availability of 
antimicrobial agents. The assessment of drug utilization is important for clinical, educational and pharmacoeconomic purposes. Though there have been several studies and reports in the literature, there are limited and inconsistent data from the Indian population. Hence, there is a need for more systematic studies to generate valid data to formulate effective guidelines for improved quality of care and therefore the present study was taken up, to describe the pattern of drugs used in acute, recurrent and chronic pharyngitis and to assess the efficacy and tolerability of the antimicrobials used in the present study.

\section{METHODS}

This observational study was done to assess the pattern of drugs used in acute, recurrent and chronic bacterial pharyngitis. After approval and clearance from the institutional ethics committee, 50 subjects with pharyngitis visiting the outpatient department of ENT at Kempegowda institute of medical sciences, hospital and research centre, Bangalore were included into the study by the investigator after coordinating and confirming the diagnosis with ENT specialist. Study subjects were recruited by purposive sampling method from January 2012-January 2013. Written informed consent was obtained from all the study subjects after fully explaining the study procedure to their satisfaction, in both English and vernacular language. Subjects fulfilling the inclusion criteria were included into the study; Patients of all age groups above 3 years, from either gender attending the OPD of ENT department with bacterial pharyngitis and willingness of the patients/parents or legal representatives to give the written informed consent and available for follow up. Patients with the following conditions were excluded from the study; Patients already receiving antimicrobial therapy, pharyngitis due to viral or fungal infections and immunocompromised patients.

Patients were subjected to a detailed history taking including personal history, family history, present and past medical history and drug history. Details of drug therapy, i.e., the intended purpose of use i.e. prophylaxis or cure, the therapeutic class of AMA used, dose, route, frequency and duration of administration, tolerability and drug interactions were recorded. After the completion of AMA therapy, the efficacy and outcome of the antimicrobial therapy was assessed by clinical examination by the ENT specialist was also documented by the investigator. Only the reported adverse drug reactions were documented after the completion of the AMA therapy. The data collected was analysed by using descriptive statistics, namely mean, standard deviation. The results were also depicted in the form of tables and Figures. Microsoft word and excel are used to generate Figures and tables.

\section{RESULTS}

Out of 50 study subjects, 26 were male and 24 were female. The mean age was $33.06 \pm 13.50$. Majority of the subjects (94\%) were between $16-45$ years, and only $6 \%$ of subjects below 16 years (Table 1). All the subjects presented with sore throat, $50 \%$ of the subjects with fever, and $12 \%$ with headache, $10 \%$ running nose, $18 \%$ with nasal obstruction, $6 \%$ with cough, and majority of the subjects $(70 \%)$ had more than one symptom (Figure 1). Most of the subjects $(96 \%)$ had the duration of symptoms of less than 10 days (among them 58\% of subjects for less than 5 days) and only $4 \%$ subjects had symptoms more than 10 days. Majority of the patients $(72 \%)$ had $1-2$ episodes, $18 \%$ with $3-4$ episodes, and only $6 \%$ with $>4$ episodes. Co-amoxiclav was used in $24 \%$ of the subjects and cefadroxil+clavulanic acid in $4 \%$, in the past one year. None of the subjects had history of allergic reactions to the commonly used AMAs like beta-lactams, fluroquinolones or macrolides. Most of the subjects had acute bacterial pharyngitis $(90 \%)$, only 2 subjects with chronic bacterial pharyngitis and 3 subjects with recurrent pharyngitis (Figure 2). Throat swab culture was done in only in 1 subject with chronic pharyngitis to confirm the causative organism and sensitivity pattern, which showed the growth of co-amoxiclav resistant S. pyogenes. Coamoxiclav which is a fixed dose combination of amoxicillin and clavulanic acid, was the most commonly used antibiotic (48\%) and other AMAs used were cefpodoxime+clavulanic acid (36\%), cefadroxil+clavulanic acid (8\%), cefpodoxime (4\%), cefuroxime $(2 \%)$ and cefixime $(2 \%)$ (Table 2$)$. In one subject with reported co-amoxiclav resistant $\mathrm{S}$. pyogenes, cefpodoxime+clavulanic acid was used. The concomitant medications used in the present study mainly included NSAIDs and decongestants/mucolytics. All the subjects received NSAIDs; $66 \%$ as fixed dose combinations which included aceclofenac+paracetamol and diclofenac+paracetamol (20\%), and monotherapy with diclofenac $(20 \%)$, nimesulide $(10 \%)$ and paracetamol (4\%) (Table 3). The outcome of therapy with various AMAs was assessed clinically after completing the course of AMA therapy. Complete cure, both subjective and objective, was seen in 13 subjects. Significant clinical improvement was observed in the other 37 subjects (Table 4). None of the subjects reported lack of improvement or worsening. Among the 13 subjects with complete cure, 8 had received co-amoxiclav and the other 4 cefpodoxime+clavulanic acid and 1 subject cefadroxil+clavulanic acid. As observed in the present study, the cure rate was $26 \%$ and clinical improvement was $74 \%$ with 5 day course of beta-lactams and the rate of resolution of infection was almost comparable with coamoxiclav and the cephalosporins. The AMAs showed good tolerability with mild and self-limiting adverse effects which did not require discontinuation. The adverse effects were mainly gastrointestinal like abdominal discomfort with distension and mild diarrhoea (Table 5). No allergic reactions were observed. Change of AMA was required in only one subject. Because of inadequate clinical improvement with 5 day course of co-amoxiclav, the therapy was changed to cefpodoxime+clavulanic acid which was continued for 5 days which resulted in complete cure. Patient compliance to the prescribed 
medications was assessed by pill count method/recovering empty packets. All the patients had complied very well to the prescribers' instructions.

Table 1: Age and socio-economic status* $(n=50)$.

\begin{tabular}{|c|c|c|c|}
\hline $\begin{array}{l}\text { Age group } \\
\text { (in years) }\end{array}$ & n $(\%)$ & $\begin{array}{l}\text { Socio- } \\
\text { economic } \\
\text { status }\end{array}$ & n $(\%)$ \\
\hline $3-15$ & $3(6.00)$ & Upper & $0(0)$ \\
\hline $16-25$ & $13(26.00)$ & $\begin{array}{l}\text { Upper } \\
\text { middle }\end{array}$ & $2(4.00)$ \\
\hline $26-35$ & $13(26.00)$ & $\begin{array}{l}\text { Lower } \\
\text { middle }\end{array}$ & $28(56.00)$ \\
\hline $36-45$ & $11(22.00)$ & $\begin{array}{l}\text { Upper } \\
\text { lower }\end{array}$ & $20(40.00)$ \\
\hline$>45$ & $10(20.00)$ & Lower & $0(0)$ \\
\hline
\end{tabular}

Mean age \pm SD $=33.06 \pm 13.50$; *Based on Kuppuswamy socio-economic status scale modified up to 1998.

Table 2: Antimicrobial agents used.

\begin{tabular}{|c|c|c|c|c|}
\hline AMAs* & Dose & Frequency & Duration & n (\%) \\
\hline Coamoxiclav & $625 \mathrm{mg}$ & BID & 5 days & $24(48.00)$ \\
\hline $\begin{array}{l}\text { Cefpodoxime- } \\
\text { clavulanic acid }\end{array}$ & $325 \mathrm{mg}$ & BID & 5 days & $18(36.00)$ \\
\hline $\begin{array}{l}\text { Cefadroxil- } \\
\text { clavulanic acid }\end{array}$ & $625 \mathrm{mg}$ & BID & 5 days & $4(8.00)$ \\
\hline \multirow{2}{*}{$\begin{array}{l}\text { Cefpodoxime } \\
\text { proxetil }\end{array}$} & $100 \mathrm{mg}^{\dagger}$ & BID & 5 days & $1(2.00)$ \\
\hline & $200 \mathrm{mg}$ & BID & 5 days & $1(2.00)$ \\
\hline $\begin{array}{l}\text { Cefuroxime } \\
\text { axetil }\end{array}$ & $250 \mathrm{mg}$ & BID & 5 days & $1(2.00)$ \\
\hline Cefixime & $160 \mathrm{mg}^{\dagger}$ & BID & 5 days & $1(2.00)$ \\
\hline
\end{tabular}

*All medications given as oral formulations for 5 days irrespective of the duration of symptoms, + Oral suspension for pediatric age group; all other formulations were used as tablets.

Table 3: Concomitant medications $(\mathbf{n}=50)$.

\begin{tabular}{|ll|}
\hline Drugs used & Number of patients \\
\hline NSAIDs & \\
\hline Aceclofenac+paracetamol & $23(46)$ \\
\hline Diclofenac+paracetamol & $10(20)$ \\
\hline Diclofenac & $10(20)$ \\
\hline Nimesulide & $5(10)$ \\
\hline Paracetamol & $2(4)$ \\
\hline Decongestants/mucolytics & \\
\hline Cetirizine+pseudoephedrine & $3(6)$ \\
\hline Phenylephrine+chlorpheniramine & $3(6)$ \\
\hline $\begin{array}{l}\text { Ambroxol+terbutaline+guaiphe } \\
\text { nesin }\end{array}$ & $1(2)$ \\
\hline Levocetirizine+pseudoephedrine & $1(2)$ \\
\hline \begin{tabular}{ll} 
Other drugs \\
\hline Rabeprazole+domperidone
\end{tabular} & $2(4)$ \\
\hline $\begin{array}{ll}\text { Omeprazole } \\
\text { Multivitamins }\end{array}$ & $1(2)$ \\
\hline $\begin{array}{l}* \\
\text { gased as adjuvants for symptomatic relief; }+ \text { For associated }\end{array}$ \\
\hline
\end{tabular}

Table 4: Outcome of therapy.

\begin{tabular}{|ll|}
\hline Outcome $^{*}$ & n $(\%)$ \\
\hline Cured $^{\ddagger}$ & $13^{\dagger}(26.00)$ \\
\hline Improved $^{\S}$ & $37(74.00)$ \\
\hline No change & $0(00)$ \\
\hline *Assessed clinically after 5 days of AMA therapy; +8 had \\
received co-amoxiclave; $\neq$ All the subjects had acute \\
pharyngitis; $\S 3$ subjects with recurrent pharyngitis, 2 with \\
chronic pharyngitis and all others had acute pharyngitis.
\end{tabular}

Table 5: Adverse effects*.

\begin{tabular}{|c|c|c|}
\hline Adverse effects & AMAs & n $(\%)$ \\
\hline \multirow[b]{2}{*}{ GI discomfort } & Co-amoxiclav & $6(12.00)$ \\
\hline & $\begin{array}{l}\text { Cefpodoxime+clavulanic } \\
\text { acid }\end{array}$ & $2(4.00)$ \\
\hline \multirow[b]{2}{*}{ Mild diarrhoea } & Cefpodoxime & $1(2.00)$ \\
\hline & $\begin{array}{l}\text { Cefpodoxime+clavulanic } \\
\text { acid }\end{array}$ & $1(2.00)$ \\
\hline $\begin{array}{l}\text { Decreased } \\
\text { appetite }\end{array}$ & $\begin{array}{l}\text { Cefpodoxime+clavulanic } \\
\text { acid }\end{array}$ & $1(2.00)$ \\
\hline
\end{tabular}

*Possibly related to AMA therapy, which were mild and selflimiting not requiring discontinuation. None of the patients had any serious adverse reactions.

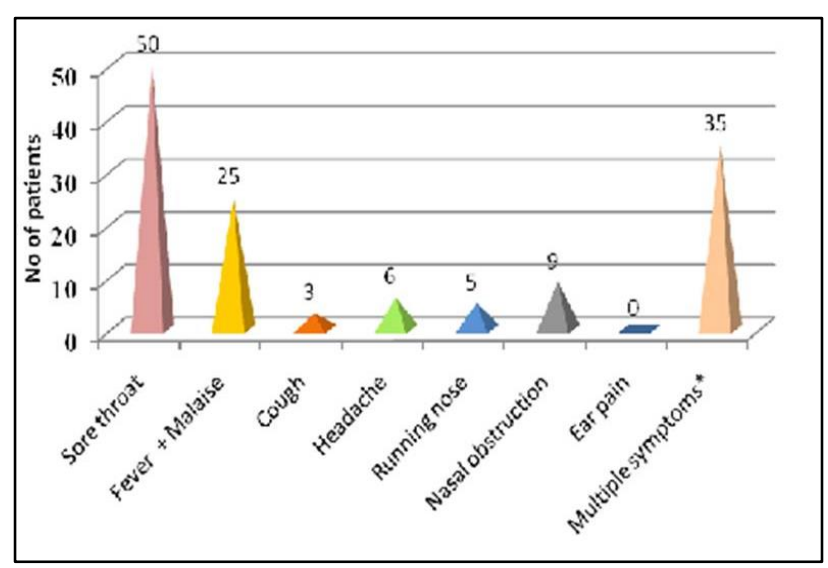

Figure 1: Presenting complaints/symptoms.

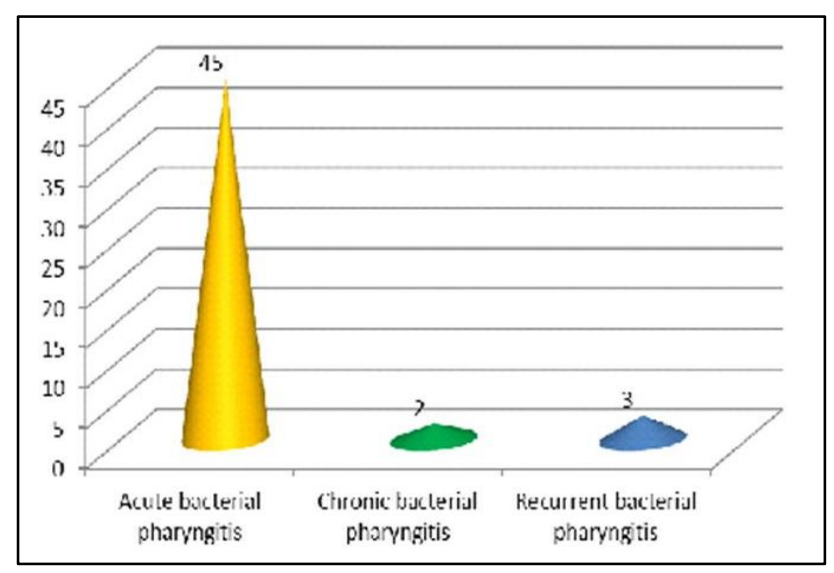

Figure 2: Diagnosis/provisional diagnosis. 


\section{DISCUSSION}

In the present study, the pattern of prescribing in bacterial pharyngitis, the criteria for their selection, their safety, tolerability and clinical outcome, was assessed in patients attending the ENT outpatient department in KIMS hospital and research centre, a tertiary care teaching hospital. All the study subjects fulfilled the inclusion and exclusion criteria and were fully compliant with the prescribed medications.

Majority of the subjects (94\%) were between $16-45$ years, and only $6 \%$ of subjects below 16 years. In other studies higher prevalence was observed in children and adolescents. ${ }^{4,5}$ This may indicate a possible geographic variation and also the fact that most of the subjects in the pediatric age group were treated by pediatricians. Majority of the subjects were from lower middle and upper lower class indicating a greater predisposition of this group for pharyngitis because of overcrowded housing and inadequate personal hygiene as reported in other studies. ${ }^{6,7}$ All the subjects presented with sore throat, $50 \%$ of the subjects with fever, similar pattern of symptoms were reported in other studies indicating that pharyngitis usually coexists with other complaints. ${ }^{8,9}$ Majority of the subjects had the duration of symptoms less than 10 days and this was consistent to the fact that most of the subjects in the present study had suffered from acute pharyngitis. Hence the duration of symptoms may correspond to the pattern of infection, acute, recurrent or chronic. Other studies have also reported a higher prevalence of acute pharyngitis compared to chronic or recurrent. ${ }^{10,11}$ None of the subjects had history of allergic reactions to the commonly used AMAs like beta-lactams, flouroquinolones or macrolides. Recording and scrutinizing the data about the previous medications may help to analyse the pattern of exposure to AMAs, to elicit any history of allergy or intolerance and also to consider any possibility of resistance to the previous AMA therapy.

Most of the subjects had acute bacterial pharyngitis, by this observation it may be presumed that the availability of effective chemotherapy has considerably reduced the chronicity and recurrence of the bacterial pharyngitis. Other studies have also reported prevalence of acute bacterial pharyngitis ranging from $52 \%$ to $89 \% .^{12}$ All the AMAs used were beta-lactams including extended spectrum penicillins, first generation, second generation and third generation cephalosporins. The AMAs were chosen empirically at the discretion of the prescribers, and in only one subject based on the throat culture report. All the AMAs were used by oral route for 5 days, irrespective of duration of symptoms. Co-amoxiclav which is a fixed dose combination of amoxicillin and clavulanic acid, was the most commonly used antibiotic. Amoxicillin is extended spectrum penicillin with good activity against most of the bacterial pathogens responsible for pharyngitis; the addition of clavulanic acid further widens the spectrum by protecting the antibiotic against bacterial beta-lactamases. The AMAs used in other studies were amoxicillin $(29.7 \%)$, macrolides $(24.3 \%)$, cephalosporins $(17.2 \%)$ and co-amoxiclav $(7.2 \%)$ which were chosen empirically and continued for 7-10 days. ${ }^{13}$ As there are no fixed and stringent guidelines, the pattern of AMA use may vary from centre to centre depending upon the pattern and prevalence of infections and the prescribing trend of the clinicians. Considering the good tolerability and cost-effectiveness, co-amoxiclav can be considered as the primary option for the initial empirical therapy of the bacterial pharyngitis, and other AMAs like cephalosporins and macrolides can be considered as a reserve options.

Concomitant medications used as adjuvants for symptomatic relief were NSAIDs and decongestants/mucolytics. Since the predominant symptom of pharyngitis is sore throat, the NSAIDs may help to relieve pain, congestion and soreness. However using the FDCs of NSAIDs can be considered irrational and only paracetamol would be suitable as adjuvant for symptomatic relief as it is free from gastric irritation and does not enhance the gastric distress likely with some of the AMAs, unlike other NSAIDs. ${ }^{5,6}$ The concomitant medications used in the present study do not seem to have any adverse interactions with AMAs other than gastric distress.

The outcome of therapy with various AMAs was assessed clinically after completing the course of AMA therapy. As observed in the present study, the cure rate was $26 \%$ and clinical improvement was $74 \%$ with 5 day course of beta-lactams and the rate of resolution of infection was almost comparable with co-amoxiclav and the cephalosporins. Other studies have reported a cure rate of more than $90 \%$ with 7-10 days course of penicillins and cephalosporins. $^{14,15}$ Some studies have reported $90 \%$ clinical improvement with 5 days of cephalosporins which was comparable to a 10 days course of oral penicillins. ${ }^{15}$ Thus it can presumed that, the minimum duration of therapy for adequate clinical improvement should be 5 days and the cure rate will be higher with more than 7 day course of therapy. The AMAs showed good tolerability (as assessed by the reported adverse events) with mild and self-limiting adverse effects which did not require discontinuation. Other studies have reported an overall incidence of adverse effects up to $2.1 \%$ which mainly included gastrointestinal $(65 \%)$ and allergic skin rashes $(23 \%)$ with no significant difference between penicillins and cephalosporins. ${ }^{15}$ Thus it appears that a short course of AMA therapy of 5-7 days is generally safe with only mild and self-limiting gastrointestinal adverse effects, unless the person is allergic to beta-lactams. There are some limitations to this study. The sample size was less and the treatment was mainly empirical.

\section{CONCLUSION}

Acute, recurrent and chronic bacterial pharyngitis can be effectively treated by empirical use of various AMAs. Co- 
amoxiclav can be considered as the mainstay or primary option because of the proven efficacy, good tolerability and low cost. Other AMAs like cefpodoxime+clavulanic acid, cefadroxil+clavulanic acid, cefuroxime, cefixime+clavulanic acid and levofloxacin can be considered as alternatives. Though a 5-day course of AMA therapy can produce a significant clinical improvement, the cure rate may be increased by continuing the AMA therapy for 7-10 days. All the AMAs showed good tolerability and patient compliance.

\section{ACKNOWLEDGEMENTS}

We are grateful to all the patients and ENT staff from KIMS hospital who contributed to this study.

Funding: No funding sources

Conflict of interest: None declared

Ethical approval: The study was approved by the Institutional Ethics Committee

\section{REFERENCES}

1. Gerber MA. Group A streptococcus. In: Kliegman RM, Jenson HB, Behrman RE, Stanton BF, editors. Nelson Textbook of Pediatrics. $18^{\text {th }}$ edition, New Delhi: Elsevier; 2008;2:1135-45.

2. Diagnosis and treatment of respiratory illness in children and adults. Institute for Clinical Systems Improvement. 2011;3:1-81. Available at https://www.icsi.org/_asset/1wp8x2/RespIllness.pdf.

3. Dhingra PL, Dhingra S. Acute and chronic pharyngitis. In: diseases of ear, nose and throat. $5^{\text {th }}$ edition. New Delhi: Elsevier; 2010:268-270.

4. Somro A, Akram M, Khan MI, Asif HM, Sami A, Ali Shah SM, et al. Pharyngitis and sore throat: A review. African Journal of Biotechnology. 2011;10(33):6190-7.

5. Shulman ST, Bisno AL, Clegg HW, Gerber MA, Kaplan EL, Lee G, et al. Clinical practice guideline for the diagnosis and management of group A streptococcal pharyngitis: Update by the infectious diseases society of America. Clinical infectious diseases. 2012;55(10):86-102.

6. Struble K, Bronze MS, Halsey ES. Bacterial pharyngitis. Medscape reference; Available at http://emedicine.medscape.com/article/225243overview. Accessed on 27 July 2013.

7. Ananthanarayan R, Paniker CKJ. Streptococcus. In: Textbook of Microbiology. $8^{\text {th }}$ edition. Hyderabad: Universities Press (India) Private Limited; 2009:204216.

8. Bisno AL, Gerber MA, Gwaltney JM, Kaplan EL, Schwartz RH. Practice guidelines for the diagnosis and management of group A streptococcal pharyngitis. Clinical Infectious Diseases. 2002;35(2):113-25.

9. Choby BA. Diagnosis and treatment of streptococcal pharyngitis. American Family Physician. 2009;79(5):383-90.

10. Regoli M, Chiappini E, Bonsignori F, Galli L, de Martino M. Update on the management of acute pharyngitis in children. Italian Journal of Pediatrics. 2011;37:10.

11. Renner B, Mueller CA, Shephard A. Environmental and non-infectious factors in the aetiology of pharyngitis (sore throat). Inflammation Research. 2012;61(10):1041-52.

12. Cohen R. Clinical efficacy of cefpodoxime in respiratory tract infection. Journal of Antimicrobial Chemotherapy. 2002;50:23-7.

13. Hong SY, Taur Y, Jordan MR, Wanke C. Antimicrobial prescribing in the U.S. for adult acute pharyngitis in relation to treatment guidelines. J Eval Clin Pract Dec. 2011;17(6):1176-83.

14. Bisno AL. Are cephalosporins superior to penicillin for treatment of acute streptococcal pharyngitis? Clinical Infectious Diseases. 2004;38:1535-37.

15. Adam D, Scholz H, Helmerking M. Short-course antibiotic treatment of 4782 culture-proven cases of group A streptococcal tonsillopharyngitis and incidence of poststreptococcal sequelae. The Journal of Infectious Diseases. 2000;182:509-16.

Cite this article as: Ranabovi D, Ramesh $\mathrm{J}$, Bisanna J, Purushothama PH. A study on the drug prescribing pattern in acute, recurrent and chronic pharyngitis at a tertiary care hospital. Int J Basic Clin Pharmacol 2016;5:1494-8. 